\title{
A INFLUÊNCIA DA LINGUAGEM ORAL NA ESCRITA: REFLEXÕES E DESAFIOS NO ENSINO DE LÍNGUA PORTUGUESA
}

The interference of orality in written language: reflections and challenges within Portuguese language teaching

La influencia del lenguaje oral en la escritura: reflexiones y desafíos en la enseñanza de la lengua portuguesa

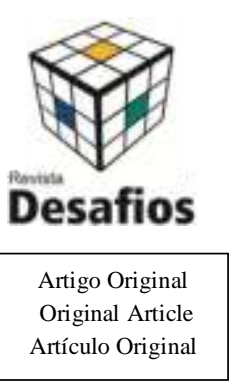

\section{Dalve Oliveira Batista-Santos ${ }^{*}$, Elemária Batista Pereira ${ }^{2}$}

${ }^{1}$ Docente do curso de Letras - Língua Portuguesa e Respectivas Literaturas, Universidade Federal do Tocantins, Tocantins, Brasil.

${ }^{2}$ Graduada em Letras, Universidade Federal do Tocantins, Tocantins, Brasil.

*Coordenação do curso de Letras. Rua 03, Quadra 17, Lote 11, S/Nº Setor Jardim dos Ipês. Porto Nacional, Tocantins, Brasil. CEP: 77500-000.E-mail:dalve@uft.edu.br

Artigo recebido em 25/02/2017 aprovado em 23/05/2017 publicado em 31/05/2017

\section{RESUMO}

O ensino de Língua Portuguesa nas últimas décadas tem enfrentado constantes desafios que permeiam questões teórico-metodológico para seu ensino. Tais questões referem-se as práticas significativas que potencializam aos educandos um agir linguageiro responsivo. Nesse contexto, o presente artigo teve por objetivo demonstrar as inadequações ortográficas que implicam marcas de oralidade de alunos do segundo ano do Ensino Médio. Para tanto, buscamos responder aos seguintes questionamentos: quais as influências/marcas da linguagem oral nos textos escritos de alunos do Ensino Médio? Como lidar, no ensino, com estas marcas e como revertê-las nas gramáticas do português padrão? Dessa forma, para respondermos aos questionamentos propostos, nos embasamos em pesquisadores que têm como foco a temática discutida nesta pesquisa, sendo eles: Marcuschi (2008; 2010); Fávero et al. (2000); Kato (2002); Bortoni-Ricardo (2004; 2005). Com as análises, constatamos que os alunos, mesmo estando no Ensino Médio, ainda utilizam a linguagem oral em seus textos escritos, o que implica pouco conhecimento das convenções ortográficas ou pouco domínio da norma culta. Além disso, acreditamos que essa influência pode ser consequência da falta de leituras significativas e orientadas, o que acarreta um repertório gramatical e enunciativo limitado.

Palavras-chave: Linguagem oral; Linguagem escrita; Língua Portuguesa.

\section{ABSTRACT}

Portuguese Language teaching has faced sustained challenges which address both theoretical and methodological issues towards its practice. Such issues refer to significant practices that provide pupils with a responsive language action. In this context, this paper aims to highlight misspellings which entail the interference of oral language into the writing of second year high school students. For this purpose, we seek to answer the following questions: what are the influences/marks of oral language in written texts of high school students? And how to handle these influences and reverse them according to the grammars of Standard Portuguese? Thus, in order to answer these questions, we support our discussion in light of the works of Marcuschi (2008; 2010); Fávero, et al. (2000); Kato (2002); Bortoni-Ricardo (2004; 2005). Through the analyses, we observed that although at the high school level, students still use oral language in their written texts, which implies either little knowledge of grammatical conventions or little mastery of the standard language. In addition, we believe that this influence may be a 
consequence of the lack of meaningful and oriented readings, which leads to a limited grammatical and enunciative repertoire.

Keywords: Oral language; Written language; Portuguese Language.

\section{RESUMEN}

La enseñanza de la lengua portuguesa, en las últimas décadas, ha enfrentado constantes desafíos que reflejan cuestiones teórico-metodológicas. Estas cuestiones se refieren a las prácticas significativas que potencían a los educandos un actuar lingüísitico responsivo. En este contexto, el presente artículo tiene por objetivo demonstrar las inadecuaciones ortográficas que implican marcas de oralidad entre estudiantes del segundo año de la escuela secundaria. Para tanto, buscamos responder a los cuestionamentos propuestos, basándonos en investigadores que tienen como foco la temática discutida en esta investigación, entre ellos: Marcuschi (2008; 2010); Fávero et al. (2000); Kato (2002); Bortoni- Ricardo (2004; 2005). Con los análisis, constatamos que los estudiantes, aunque estudien en la escuela secundaria, todavía utilizan el lenguaje oral en sus textos escritos, lo que implica poco conocimiento de las convenciones ortográficas o poco dominio de un conocimiento apropiado. Además, creemos que esta influencia puede ser consecuencia de la ausencia de lectura significativa y orientada, lo que resulta en un repertorio gramatical limitado.

Palabras Clave: lenguaje oral; lenguaje escrito; lengua portuguesa

\section{INTRODUÇÃO}

A fala e a escrita possuem elementos diferentes, próprios e, por utilizar o mesmo sistema linguístico, não devem ser discutidas de forma dicotômica, pois, como afirma Marcuschi (2010, p. 21), "a passagem da fala para a escrita não é a passagem do caos para a ordem: é a passagem de uma ordem para outra ordem". Assim, a oralidade e a escrita não podem ser entendidas no nível de superioridade ou inferioridade em relação à outra.

Sendo assim, nosso objetivo, com este artigo, foi demonstrar as inadequações ortográficas que implicam marcas de oralidade de alunos do segundo ano do Ensino Médio. Para tanto, buscamos responder aos seguintes questionamentos: quais as influências/marcas da linguagem oral nos textos escritos de alunos do Ensino Médio? Como lidar, no ensino, com estas marcas e como revertê-las nas gramáticas do português padrão?

Dessa forma, para respondermos aos questionamentos supracitados, selecionamos dentre as amostras de textos coletadas em uma oficina de produção textual quatro redações que apresentavam notoriamente as inadequações ortográficas, atendendo aos objetivos do artigo. Levando em consideração que todas os texto apresentavam inadequações ortográficas, a seleção foi feita de maneira aleatória, não tendo um critério específico e os textos foram coletados durante a realização dessa oficina numa escola pública, situada na periferia do município de Porto Nacional, no estado do Tocantins. Em seguida, fizemos as análises, procurando verificar a ocorrência de inadequações ortográficas que implicam marcas de oralidade na escrita desses alunos, seguindo o critério estabelecido por Bortoni (2005, p. 54) "erros decorrentes da transposição dos hábitos da fala para a escrita”.

Justificamos a escolha da temática a ser discutida neste artigo a partir da necessidade de refletirmos a relação entre oralidade e escrita. Além disso, a razão da escolha deve-se ao fato de podermos contribuir com o ensino da Língua Portuguesa (LP), com a finalidade de proporcionar uma reflexão acerca do papel do professor de LP, enquanto agente transformador. 
Nosso referencial teórico está respaldado em estudiosos da temática aqui proposta, que se debruçaram nas últimas décadas em questões que envolvem a fala e a escrita, sendo eles: Marcuschi, (2008/2010); Fávero, Andrade e Aquino (2000); Kato (2002); Bortoni-Ricardo (2004). Segundo eles, a fala e a escrita mantêm relação de dependência e são muito importantes no desenvolvimento da Língua Materna. Marcuschi (2008), por exemplo, assevera que, de maneira equivocada, muitos indivíduos caracterizam a oralidade como algo mais fácil, solta e sem regras e já a escrita possui suas convenções ancoradas na Gramática.

Destarte, para melhor compreensão da nossa proposta, optamos em organizá-la em três seções. Na primeira seção, trouxemos uma discussão acerca da oralidade e escrita, apresentando definições e concepções de teóricos da área. Na segunda, apresentamos as ocorrências de inadequações ortográficas que implicam marcas de oralidade na escrita dos alunos influência. Na terceira seção, discutimos as análises dos textos selecionados. Por fim, tecemos considerações finais acerca do estudo.

\section{A ORALIDADE E A ESCRITA: CONCEPÇÕES E REFLEXÕES}

Nesta seção, abordamos as concepções e reflexões de linguagem oral que alguns autores apresentam em suas pesquisas sobre a oralidade e a escrita, apontando definições, reflexões críticas e concepções a partir de diversas perspectivas.

A partir de 1980, algumas obras (Marcuschi (2008; 2010); Fávero, Andrade e Aquino (2000); Kato (2002) e Koch (2005)) começaram a investigar de maneira significativa a modalidade oral, não a vendo como modalidade oposta à escrita (MARCUSCHI, 2010). Ainda sofrendo grande influência da perspectiva estruturalista, a fala estava em segundo plano, não sendo objeto de investigação, pois, para o Saussure, o sistema da língua merecia análise. Com esta visão, o código era privilegiado, sendo considerado objeto de análise. Importa dizermos, que o estruturalismo abriu vias para o estudo das sincronias e de suas mudanças sociais. do autor),

Segundo Marcuschi (2010, p. 17, grifos

[...] sob o ponto de vista mais central da realidade humana, seria possível definir o homem como um ser que fala e não como um ser que escreve. Entretanto, isto não significa que a oralidade seja superior à escrita, nem traduz a convicção, hoje tão generalizada quanto equivocada, de que a escrita é derivada e a fala é primária. A escrita não pode ser tida como uma representação da fala.

$\mathrm{O}$ autor discute que o homem pode ser definido como um ser que desenvolve mais a fala do que a escrita, e uma não é superior à outra. Para ele, não é correto dizer que há entre as duas uma relação de derivação, tampouco devemos considerar a escrita um modo de o homem representar sua fala, pois as duas modalidades pertencem ao mesmo sistema linguístico.

Alguns pesquisadores apontam que a oralidade não influencia nada a escrita (dentre eles, BOTELHO, 2005), já outros (como por exemplo, CAGLIARI, 1993) enfatizam que a oralidade influencia na escrita, pois o autor do texto, ao escrevê-lo, não utilizará contextos informais; ele assumirá na verdade uma posição enunciativa específica da enunciação oral, que é valorada como oral. Notamos dessa forma, uma questão enunciativa e discursiva, e não apenas contextual. 
Essas discussões levaram muitos a compreenderem, como foi dito na introdução deste artigo e pensamos ser pertinente repetir, que "a passagem da fala para a escrita não é a passagem do caos para a ordem: é a passagem de uma ordem para outra ordem", (MARCUSCHI, 2010, p. 21), ou seja, tanto a fala quanto a escrita possuem suas regras as suas ordens. Mas uma não é superior a outra. A fala, segundo Bessa $e t$ al. (2012, p. 203), possui componentes pragmáticos, "pausas, hesitações, alongamentos de vogais e consoantes, repetições, ênfases, truncamentos etc.," dando a esta modalidade uma característica de espontaneidade, dinamicidade, simplicidade e informalidade, peculiaridades que não poderiam ser aplicadas à escrita, exceto em (alguns) textos literários que requerem um estilo peculiar a sua forma.

É preciso que os sujeitos percebam que a fala é diferente da escrita e que ambas possuem gramáticas (sintaxes diferentes) e estão distribuídas em um contínuo que faz a fala atravessar a escrita e a escrita inclusive marcar a aquisição da fala. A fala depende muito do ambiente em que os sujeitos estão inseridos, e a escrita tem normas de registro a serem seguidas (no caso da Língua Portuguesa, trata-se de uma ortografia em primeiro plano e depois de gêneros cristalizados a partir de algumas normas linguísticas diferentes). $\mathrm{Na}$ perspectiva de Marcuschi (2010, p. 21), "a oralidade seria uma prática social interativa para fins comunicativos que se apresenta sob várias formas ou gêneros textuais fundados na realidade sonora: ela vai desde uma realização mais informal a mais formal nos vários contextos de uso".

A linguagem oral está relacionada a vários fatores (BORTONI-RICARDO, 2004) como, por exemplo: idade, sexo, raça, profissão, posição social, grau de escolaridade, classe que pertence na sociedade. Todos esses fatores implicam na hora da produção escrita. São elementos de constituição do escritor que influenciam diretamente no processo de construção textual. Por exemplo, o grau de escolaridade interfere, pois o indivíduo que teve a oportunidade de estudar tende a "dominar mais" a escrita do que aquele que não teve tanto contato com ela.

Assim, tomando a escrita como uma forma de comunicação entre indivíduos, podemos entender as diferenças de verbalização oral e escrita e outros aspectos textuais como coesão, coerência, o português padrão e não padrão e verificar a representação do que os alunos pensam sobre determinado assunto. NA maioria das vezes, de maneira equivocada (se levarmos em consideração os estudos do letramento), clareza e objetividade são critérios essenciais de uma boa escrita, pois assim o sujeito possui mais chances de cumprir as normas da língua relativas a essa atividade. Vemos nessa perspectiva, a 'concepção da linguagem como espelho do pensamento' (A linguística tem criticado bastante essa concepção já desde a década de 60), pois clareza e objetividade é questão enunciativa e distribuída por gêneros do discurso, não é uma propriedade da escrita.

Logo, por meio da escrita dos alunos, e claro que pela linguagem oral também, é possível identificar quais as suas dificuldades e habilidades com a Língua Portuguesa. No contexto educacional, exige-se, dependendo do contexto, o registro da escrita na linguagem culta, ou seja, o português padrão, coerente ao gênero que se solicita para que seja escrito.

Um texto que apresenta desvios de registros, por mais que tenha coerência, requer um cuidado, 
pois a escrita possui suas particularidades no processo de concretização do ato de escrever (ortografia e sintaxe estandardizada). Escrever não é só decifrar códigos, é um processo no qual o escritor tem que possuir argumentos convincentes ao leitor.

Para se criar um bom texto, tanto na modalidade oral, quanto na escrita é preciso ler, reler, escrever, reescrever; essas atividades dão ao aluno a possibilidade de desenvolver de maneira significativa sua escrita.

Nessa linha de pensamento, Koch (2005, p. 78) apresenta algumas características da língua falada e da língua escrita, para criticar uma dicotomia existente entre as duas modalidades, como elencadas no quadro a seguir:

Quadro 01. Características da fala e escrita

\begin{tabular}{|c|c|}
\hline FALA & ESCRITA \\
\hline Contextualizada & Descontextualizada \\
\hline Implícita & Explícita \\
\hline Redundante & Condensada \\
\hline Não-planejada & Planejada \\
\hline Predominância do "modus pragmático" & Predominância do "modus sintático" \\
\hline Fragmentada & Não fragmentada \\
\hline Incompleta & Completa \\
\hline Pouco elaborada & Elaborada \\
\hline Pouca densidade informacional & Densidade Informacional \\
\hline $\begin{array}{l}\text { Predominância de frases curtas, simples ou } \\
\text { coordenadas }\end{array}$ & $\begin{array}{l}\text { Predominância de frases completas subordinação } \\
\text { abundante }\end{array}$ \\
\hline Pequena frequência de passivas & Emprego frequente de passivas \\
\hline Pouca nominalização & Abundância de nominalizações \\
\hline Menor densidade lexical & Maior densidade lexical \\
\hline
\end{tabular}

Fonte: Koch (2005, p. 78).

Podemos inferir, a partir do quadro acima, que as próprias características relacionadas à fala remetem a um pensamento de desvalorização desta modalidade por parte dos sujeitos em comparação com a escrita. Não 
descontextualizada, não-planejada e incompleta, dando margens a concepções equivocadas.

Diante das características apresentadas no quadro 01, devemos compreender que nem sempre elas se referem apenas a uma única modalidade, pois, como afirma Nobre e Fávero (2011, p. 05), "o gênero do texto analisado é que exige e/ou permite o intercâmbio entre as duas modalidades". Ainda segundo as autoras, as características supracitadas, na maioria das vezes, levam em consideração padrões linguísticos préestabelecidos para a modalidade escrita, e tais padrões concebem o que as pesquisadoras (2011, p. 05) denominam "de uma visão preconceituosa da fala", comparando-a com o processo de aquisição da linguagem de crianças e a forma de comunicação das sociedades primitivas.

No texto escrito, em sua elaboração, quem o faz tem o maior tempo de planejamento, pode fazer rascunhos, revisões e as correções necessárias; já na modalidade oral, em seu momento, a fala é o próprio rascunho, podemos falar e corrigir em seguida. $\mathrm{O}$ discurso ocorre em descontinuidades frequentes, por questão da interação.

A modalidade oral possui diversos gêneros que a representa, tais como: diálogos familiares, discurso acadêmico, conversas entre amigos, entrevistas jornalísticas. Portanto, há alguns textos falados (gêneros orais) que possuem características da escrita, porque exigese deles um cuidado em relação à situação de comunicação e às convenções de língua. Assim, também há textos escritos que apresentam modalidade da língua oral.

Compreendemos que tanto a língua oral, quanto a língua escrita fazem parte do nosso cotidiano e, segundo os PCN (1998, p. 15), a apropriação dessas duas modalidades é de extrema importância: [...] para a participação social efetiva, pois é por meio dela que o homem se comunica, tem acesso à informação, expressa e defende pontos de vista, partilha ou constrói visões de mundo, produz conhecimento (BRASIL, 1998, p. 15).

Nessa perspectiva, a escrita e a fala possuem uma importância ainda maior se levarmos em conta o fato de que são duas formas de nos comunicarmos uns com os outros. O indivíduo pode estabelecer uma comunicação escrevendo ou falando, pois essas duas formas de verbalização humana existem para que possamos compreender um ao outro por meio da interação social.

\section{A INFLUENCIA DA ORALIDADE NA ESCRITA}

Diante do que foi discutido até aqui, compreendemos que a linguagem oral e a escrita possuem características diferentes, porém podemos encontrar marcas da primeira em textos escritos, pois algumas pessoas não percebem que fazem a utilização da linguagem oral em sua escrita. Além disso, pode não ser apenas uma questão de percepção do falante; é uma questão de valoração enunciativa e aprendizagem de gramáticas, ou seja, de aquisição linguística. Dessa forma, inferimos que nas pesquisas voltadas para linguagem existe uma relação [...] interativa e complementar entre essas duas modalidades do sistema linguístico, e a língua, por sua vez, é considerada a partir de suas condições de produção e recepção, o que provocou uma guinada nos estudos linguísticos. (BESSA, et al., 2012, p. 202). 
Dessa maneira, aprendemos que esse novo olhar para os estudos da linguagem possibilitou levar em consideração o contexto sócio-histórico das práticas linguageiras, e a oralidade passou a ganhar um enfoque tão importante quanto o dado à escrita, haja vista que, em alguns casos, esta sofre influência daquela.

Quando o aluno escreve o seu texto não percebe que algumas características próprias da fala não devem estar presentes na escrita, como, por exemplo, o uso de gírias (que na maioria das vezes é utilizado em contextos informais de utilização da linguagem), esquecendo-se das normas de registros que regem nossa língua, ocasionando a transcrição literal do oral para escrita.

A falta de um repertório linguístico amplo pode influenciar na hora da escrita, implicando numa incidência maior de inadequações de escrita (regras gramaticais). Com essa incidência as marcas da oralidade se tornam evidentes na produção textual dos sujeitos. A falta de leituras implica, sem dúvida, na hora de escrever. O vocabulário do aluno fica limitado e ele acaba cometendo equívocos no registro de algumas palavras porque associa a pronúncia à escrita.

Dessa forma, a influência da fala na escrita ocorre por serem próximas uma da outra. Muitas vezes, o aluno escreve da forma como fala, pelo fato de tanto pronunciar certas palavras durante sua interação com outros membros da sociedade e não perceber que a fala não deveria estar presente em suas produções escritas. Para Souza (2001), devemos levar em consideração a concepção de que a escrita e fala são realizações orais e letradas, "mas há variação na forma pela qual as atividades linguísticas são distribuídas entre as duas modalidades devido a diferenças temporais, sociais e individuais (SOUZA, 2001, p. 25).

Sob essa visão, podemos compreender que a escrita é mais convencional do que a fala, porém, em alguns textos escritos, encontramos marcas da oralidade. Por isso, não devemos dizer que a escrita é superior a fala, mas que as duas, por pertencerem ao mesmo sistema linguístico, possuem sua importância na língua portuguesa. Segundo Souza (2001, p. 26), a fala e a escrita possuem "[...] padrões de lexicogramaticalização preferidos, que podem aparecer cruzados, em situações inesperadas segundo a intenção do falante".

Assim, poderemos encontrar textos típicos da linguagem oral, que primeiramente passam pela modalidade escrita. São os casos dos gêneros: conferência, reunião de trabalho, repente, palestra, e etc. A respeito disso, Batista-

[...] a conferência, antes de ser concretizada, exige que o enunciador apoie em textos escritos para fundamentar seu pensamento e, durante a conferência, ele utiliza-se de um texto escrito, impresso ou apresentado no Power Point (preparados previamente). Depois, essa conferência pode ser publicada em livros ou anais de eventos na forma de artigo científico.

Vale ressaltar que fatores socioculturais estão inerentemente interligados à modalidade oral a qual influencia, de maneira significativa, a escrita. Nessa linha de pensamento, Marcuschi (2010, p. 35) afirma que

[...] a língua, seja na sua modalidade falada ou escrita, reflete, em boa medida, a organização da sociedade. Isso porque a própria língua mantém complexas relações com as representações e as formações 
sociais. Não se trata de um espelhamento, mas de uma funcionalidade em geral mais visível na fala. É por isso que podemos encontrar muitos correlatos entre variação sociolinguística e variação sociocultural.

Diante do exposto, podemos inferir que a oralidade possui características diferentes, e não dicotômicas, da escrita e esta sofre influência de vários fatores, que poderão estar relacionados ao processo de ensino e aprendizagem (como por exemplo, falta de leitura, falta de atenção com a escrita e etc.). Em um texto dissertativo, por exemplo, algumas convenções de língua são exigidas para concretização dele (composição, estilo, etc.), o que torna imprescindível a atenção acerca desta influência.

\section{PRÁTICA DE ENSINO DA ORALIDADE E ESCRITA: UM OLHAR PARA SALA DE AULA}

Iniciamos essa discussão apresentando uma reflexão dos PCN (1998, p. 67), acerca do que representa o ensino da oralidade para escola, pois, segundo este documento, o ensino da oralidade para esta instituição deve representar "acesso a usos da linguagem mais formalizados e convencionais, que exijam controle mais consciente e voluntário da enunciação, tendo em vista a importância que o domínio da palavra pública tem no exercício da cidadania”.

A escola e os professores se sentem na obrigação de ensinar os alunos a dominarem a língua escrita, mas não se sentem estimulados a ensiná-los a se apropriarem de maneira efetiva da língua oral, pois acredita-se na maioria das vezes que a língua falada já foi apreendida em casa, nessa linha de pensamento Castilho (1998, p. 13) afirma que
[...] não se acredita mais que a função da escola deve concentrar-se apenas no ensino da língua escrita, a pretexto de o aluno já aprendeu a língua falada em casa. Ora, se essa disciplina se concentrasse mais na reflexão sobre a língua que falamos, deixando de lado a reprodução de esquemas classificatórios, logo se descobriria a importância da língua falada, mesmo para a aquisição da língua escrita.

Dessa forma, acreditamos que a escola, por ser uma instituição que permite a aquisição de saberes diversos, deveria promover atividades que possibilitem o desenvolvimento da linguagem oral e não só na modalidade escrita, que é privilegiada pela sociedade, pois, como afirma Kato (2002, p. 7), a função da escola, intermediada pelo professor, é "desenvolver no aluno o domínio da linguagem falada institucionalmente aceita". Seguindo essa mesma linha de pensamento, Bortoni-Ricardo (2005, p. 49), afirma que a função da escola

[...] no processo de aquisição da linguagem, não é ensinar o vernáculo, pois este os alunos já trazem consigo ao iniciar a escolarização, pois o adquirem na sua rede primária de relações, constituída da família e vizinhos. A função da escola é justamente desenvolver outras variedades que se vão acrescer ao vernáculo básico.

Devemos considerar os conhecimentos prévios que o aluno já traz consigo e ajudá-lo a explorá-los mais, pois a escola possui mecanismos capazes de ampliar os conhecimentos dos alunos, e cada um deles possui seu grau de facilidade ou dificuldade no processo de aquisição da linguagem, que será trabalhado por meio da mediação do professor. Nesse processo, o professor deverá levar em consideração que, na maioria das vezes, 
[...] o aluno segue a regra da fidelidade ensinada desde a alfabetização, escreve como se fala; segundo, que ele só pode fazer uso daquilo que ele tem: a sua variedade linguística, que em geral não é aceita pela escola. Assim, as marcas de oralidade que aparecem nos textos dos alunos, obedecendo ao princípio da fidelidade ensinado desde a alfabetização, são provas cabais de que os alunos foram mal alfabetizados. (FRANÇA, 2009, p. 03).

Nesse contexto, devemos compreender, acima de tudo, que a linguagem oral é diferente da linguagem escrita, pois a escrita apresenta [...] características próprias que não se encontram na fala, como tamanho e tipo das letras, cores e formatos, elementos pictóricos que funcionam como gestos e mímica graficamente representados. (FAVERO e NOBRE, 2011, p. 03).

Essa diferença deve ser refletida na forma como elas são ensinadas na sala de aula, pois, na maioria das vezes, apenas a escrita tem um lugar privilegiado neste processo, tornando a oralidade marginalizada, num segundo plano ou, até mesmo, não sendo considerada como tema de ensino.

A oralidade, algumas vezes é trabalhada em sala de aula, em forma de leitura em voz alta. Essa prática nos remete à concepção de linguagem como representação do pensamento (Kleiman, 2013). Outra atividade que é bem utilizada para se trabalhar a modalidade oral é o debate e a dramatização, que também são consideradas, equivocadamente, como suficientes para desenvolvimento desta modalidade. Essa forma restrita de se trabalhar a oralidade pode ser despreparo por parte do professor que, em sua formação, não tiveram esta temática discutida de forma significativa e relevante às práticas pedagógicas.
Acreditamos que o professor poderia, durante esse processo, além de possibilitar atividades que desenvolvam a linguagem escrita, também proporcionar práticas com gêneros orais com a mesma dinamicidade, pois a atividade que envolve a linguagem oral é tão importante quanto a escrita.

\section{Nessa perspectiva Bortoni-Ricardo}

(2006, p. 268) afirma que

[...] é nossa tarefa na escola ajudar aos alunos a refletir sobre sua língua materna. Essa reflexão torna mais fácil para eles desenvolver sua competência e ampliar o número e a natureza das tarefas comunicativas que já são capazes de realizar, primeiramente na língua oral e, depois, por meio da língua escrita.

Seguindo essa linha de pensamento, Batista-Santos (2014) ressalta a importância de se trabalhar com a modalidade escrita e a modalidade oral, pois, para referida pesquisadora,

[...] a fala e escrita ocorrem num contínuo. Dessa forma, as novas perspectivas de texto, gênero, discurso, suas condições de produção e realização. Há uma revisão da forma de conceber a fala, pois a fala, tida antes como lugar da desorganização, espontaneidade, passa agora a ser vista como planejada e organizada segundo critérios que favorecem a interação e compreensão do que é dito (BATISTASANTOS, 2014, p. 50).

Nesse sentido, já que o mito da fala como lugar da desorganização é revisto, o ensino dela também deve ser repensado, pois acreditamos que, assim como a modalidade escrita é ensinada, a fala também deve ser ensinada, levando seu processo de realização (características próprias de cada modalidade).

A pesquisadora Bortoni-Ricardo (2005, p. 54), levando em consideração os desafios 
enfrentados pelo professor de LP, propõe duas categorias de erros ${ }^{1}$. A primeira diz respeito aos "erros decorrentes da própria natureza arbitrária do sistema de convenções da escrita". Assim seriam os desvios resultantes do conhecimento insuficiente por parte dos alunos, em relação às arbitrariedades ortográficas. A segunda categoria se refere aos "erros decorrentes da transposição dos hábitos da fala para a escrita" (ibidem, p. 54), que são os desvios em relação:

a) a interferência de regras fonológicas categóricas no dialeto estudado (vocábulos fonológicos constituídos de duas ou mais formas livres ou dependentes grafados como um único vocábulo formal; crase entre vogal final de uma palavra e vogal idêntica ou foneticamente próxima da palavra seguinte; neutralização das vogais anteriores /e/ e /i/ e das posteriores /o/ e /u/ em posição pós-tônica ou pré-tônica; nasalização do ditongo em "muito" por assimilação progressiva.

b) a interferência de regras fonológicas variáveis graduais (despalatização das sonorantes palatais (lateral e nasal); monotongação de ditongos decrescentes; ditongação da vogal anterior /e/ por assimilação da fricativa palatal sonora /j/; desnasalização das vogais átonas finais; assimilação e degeminação do /nd/: /nd > nn > n/; queda do /r/ final nas formas verbais; supressão do morfema flexional de concordância da língua-padrão).

c) a interferência de regras fonológicas variáveis descontínuas (semivocalização do /lh/;

\footnotetext{
${ }^{1}$ A autora justifica a utilização do termo "erros" uma vez que a fala prevê a variação, já a escrita não. "Na linguagem escrita o chamado erro tem uma outra natureza porque representa a transgressão de um código convencionado e prescrito pela ortografia" (BORTONI-RICARDO, 2006, p. 273).
}

epítese do /i/ após sílaba final travada; troca do /r/ pelo /l/; monotongação do ditongo nasal em "muito" >> muntu; supressão do ditongo crescente em sílaba final; simplificação dos grupos consonantais no aclive da sílaba com a supressão da segunda consoante; metátese em "satisfeito" >> sastifeito). Salientamos que, os textos selecionados serão analisados, procurando verificar a ocorrência de marcas de oralidade na escrita desses alunos, seguindo a segunda categoria proposta por Bortoni-Ricardo (2005).

Diante do exposto e levando em consideração as inadequações encontradas nos textos dos alunos, sugerimos atividades que possibilitem o desenvolvimento significativo dos referidos alunos na modalidade escrita e na modalidade oral. Assim, Fávero, Andrade e Aquino (2000) propõem atividades que possibilitam o desenvolvimento da modalidade oral e escrita: a) por meio de textos orais produzidos e gravados pelos discentes, em que eles irão identificar temas e subtemas, para depois produzirem textos escritos, observando sua estruturação e paragrafação; b) verificar traços da oralidade em gêneros jornalísticos, compreendendo os efeitos de sentido e no gênero crônica, caracterizando os personagens; e c) proporcionar atividades em que os alunos comparem gêneros orais e escritos produzidos pelo mesmo autor e mais dois gêneros produzidos por autores diferentes, em contextos distintos de comunicação.

Seguindo essa mesma linha, Marcuschi (2010) propõe atividades como a retextualização como forma dos sujeitos desenvolverem as duas modalidades. O autor sugere que, a partir de um gênero oral, os alunos, no processo de reescrita, consigam elaborar outros textos, não perdendo a ideia central, mas modificando o original. Dessa 
forma, atividades como essas (sabemos que existem outras formas) possibilitam ao professor ferramentas para o desenvolvimento das habilidades orais e escritas dos sujeitos.

Por fim, diante do discutido, compreendemos que cabe à escola trabalhar todas as modalidades da linguagem (verbal - oral e escrita - e não-verbal), possibilitando o desenvolvimento efetivo dos sujeitos em relação às práticas letradas que envolvem a fala e a escrita, pois segundo Bortoni-Ricardo (2004, p. 75), a escola é considerada "por excelência, o locus - ou espaço - em que os educandos vão adquirir, de forma sistemática, recursos comunicativos que lhes permitam desempenharse competentemente em práticas sociais especializadas".

\section{MARCAS DA ORALIDADE NA ESCRITA: ANÁLISE E DISCUSSÃO}

Nesta seção, apresentamos a metodologia adotada na pesquisa e a análise das redações evidenciando a influência da oralidade na escrita. Para tanto, levamos em consideração o discutido nas seções anteriores.

\section{CONTEXTO DA PESQUISA E COLETA DE DADOS}

Para a realização deste trabalho, utilizamos amostras de textos coletados, pertencentes aos gêneros crônica e artigo de opinião. Os dois gêneros trabalhados são pertencentes à modalidade escrita. $\mathrm{O}$ gênero crônica é um gênero com predominância da tipologia narração e, segundo Araújo e Barbosa (2013, p. 331), ele

[...] surgiu no início do século XIX na época da escola literária modernista a partir de publicações em folhetins, os quais tratavam de diversos assuntos presentes na vida diária social da época, mas tinha por principal finalidade distrair os leitores lhes proporcionando momentos de distração através da imaginação e reflexão sóciocrítica.

Diante do exposto, compreendemos que esse gênero é importante por possibilitar ao aluno uma reflexão sobre assuntos do dia a dia e próximos à sua realidade. Em relação ao artigo de opinião, sabemos que ele tem a predominância da tipologia argumentação, em que o autor apresenta um determinado tema e seu ponto de vista. Este gênero pode ser redigido em primeira ou terceira pessoa do discurso, apresentando introdução, desenvolvimento e conclusão. Assim, da mesma forma que o gênero crônica é representado na modalidade escrita, o gênero artigo de opinião também.

Para constituição do corpus desta pesquisa, o primeiro passo, depois de muitas leituras que embasaram, teoricamente, nossos conhecimentos sobre a influência da oralidade na escrita, foi selecionar, dentre as amostras de textos coletadas quatro redações frutos de uma oficina de Produção textual.

A oficina foi realizada com alunos do segundo ano do Ensino Médio, com faixa etária de 16 a 19 anos, numa escola pública, situada na periferia do município de Porto Nacional, no estado do Tocantins e as redações selecionadas pertenciam aos gêneros artigo de opinião e crônica.

Nesta seção, analisamos as marcas da oralidade nos textos dos alunos. Porém, salientamos que, mesmo os textos apresentando desvios em relação a primeira categoria, os "erros decorrentes da própria natureza arbitrária do sistema de convenções da 
escrita" (sintaxe, ou ortografia), não a evidenciaremos levando em consideração que este não é o foco da presente pesquisa (BORTONI-RICARDO, 2005, p. 54).
Demonstramos, a seguir, um levantamento das principais ocorrências que exemplificam essas marcas.

Texto 1. Análise das produções dos alunos

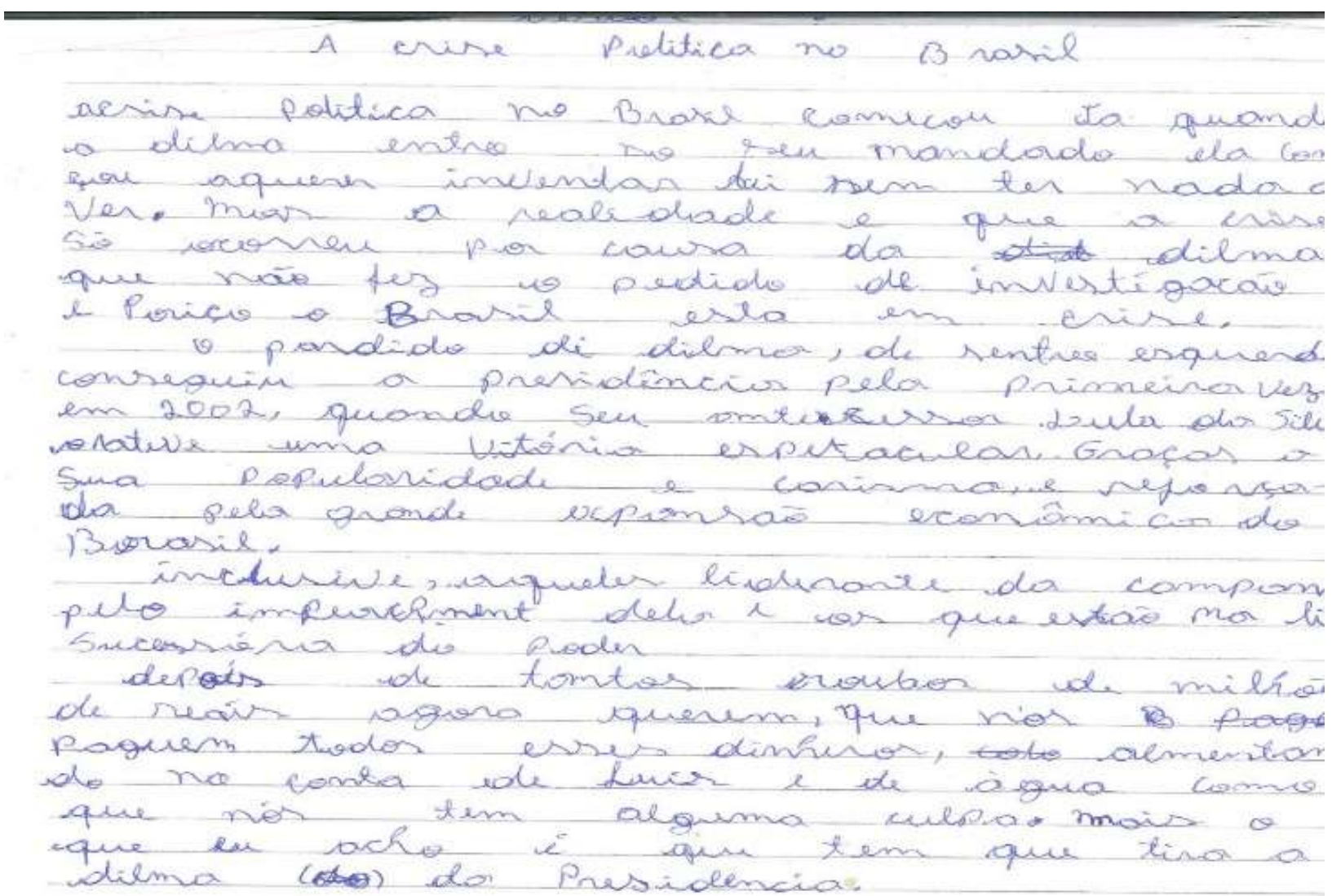

Diante do texto, percebemos a ocorrência de marcas da oralidade em relação a:

a) Erros decorrentes da interferência de regras fonológicas categórica no dialeto estudados:

- $\quad$ aluno também faz a junção do som nas palavras "por isso", e escreve "poriço" (formação de grupos de força). Percebemos, assim, o fenômeno da hipossegmentação, que segundo BortoniRicardo (2005), diz respeito a um tipo de grafia que desconsidera os limites gráficos da palavra, em razão da influência da prosódia.
Nessa categoria Bortoni-Ricardo (2005) insere os vocábulos fonológicos constituídos de duas ou mais formas livres ou dependentes grafadas como um único vocábulo formal ('acrise'; 'poriço').

b) Erros decorrentes da interferência de regras Fonológicas variáveis graduais

- Queda do /r/ final nas formas verbais: "tira" (tirar).

Cagliari (1993, p. 65) relata para este caso que, "alguns alunos deixam de assinalar a letra $r$ de certas palavras porque segundo suas pronúncias não ocorre nenhum som que eles reconheçam como pertencendo à categoria do $\mathrm{r}$. 
Por exemplo, há alunos que escrevem acha (em vez de achar)".

- Monotongação de ditongos decrescentes: "dinheros" (dinheiros). Esse fenômeno é típico da fala espontânea.

- Ditongação (luz $\neq$ luis); Substituições envolvendo a grafia de fonemas surdos e sonoros (trocas de consoantes /z/ pela consoante /s/ "luis" no lugar de luz).

- Supressão e acréscimo de letras $\rightarrow$ Troca o d pelo t: "mandado" (mandato); "pardido" (partido). Esse desvio é considerado, na maioria das vezes, como algo grave (troca de surda/sonora), remetendo ao aluno a um tratamento de fonoaudiólogo.

Cagliari (1993, p. 63) ressalta que:

A distinção entre consoantes surdas e sonoras depende ainda do dialeto que a criança fala, pois, a palavra para um aluno pode conter um [p], um [t] ou um [s], dependendo das variações dialetais. Isso torna também difícil aprender a ortografia das palavras.

c) Erros decorrentes da interferência de regras Fonológicas variáveis descontínuas
- Supressão do ditongo crescente em sílaba final ("entro" no lugar de "entrou”);

\section{d) Outras marcas:}

- Alguns desvios de pontuação que remetem às atividades conversacionais, sem pausas, falas seguidas/contínuas (inclusive, aqueles liderante $d a$ campanha pelo impeckment dela e os que estão na linha sucessória do poder depois de tantos roubos de milhões de reais agora querem), o que dificulta compreender o sentido contido no texto. Isso nos leva a inferir que o aluno realiza tal ação por entender que a fala é contínua;

Compreendemos que esses desvios são uma ilustração clara de como as marcas da oralidade podem se manter presentes na produção escrita quando não se é trabalhado de maneira mútua as duas modalidades. 


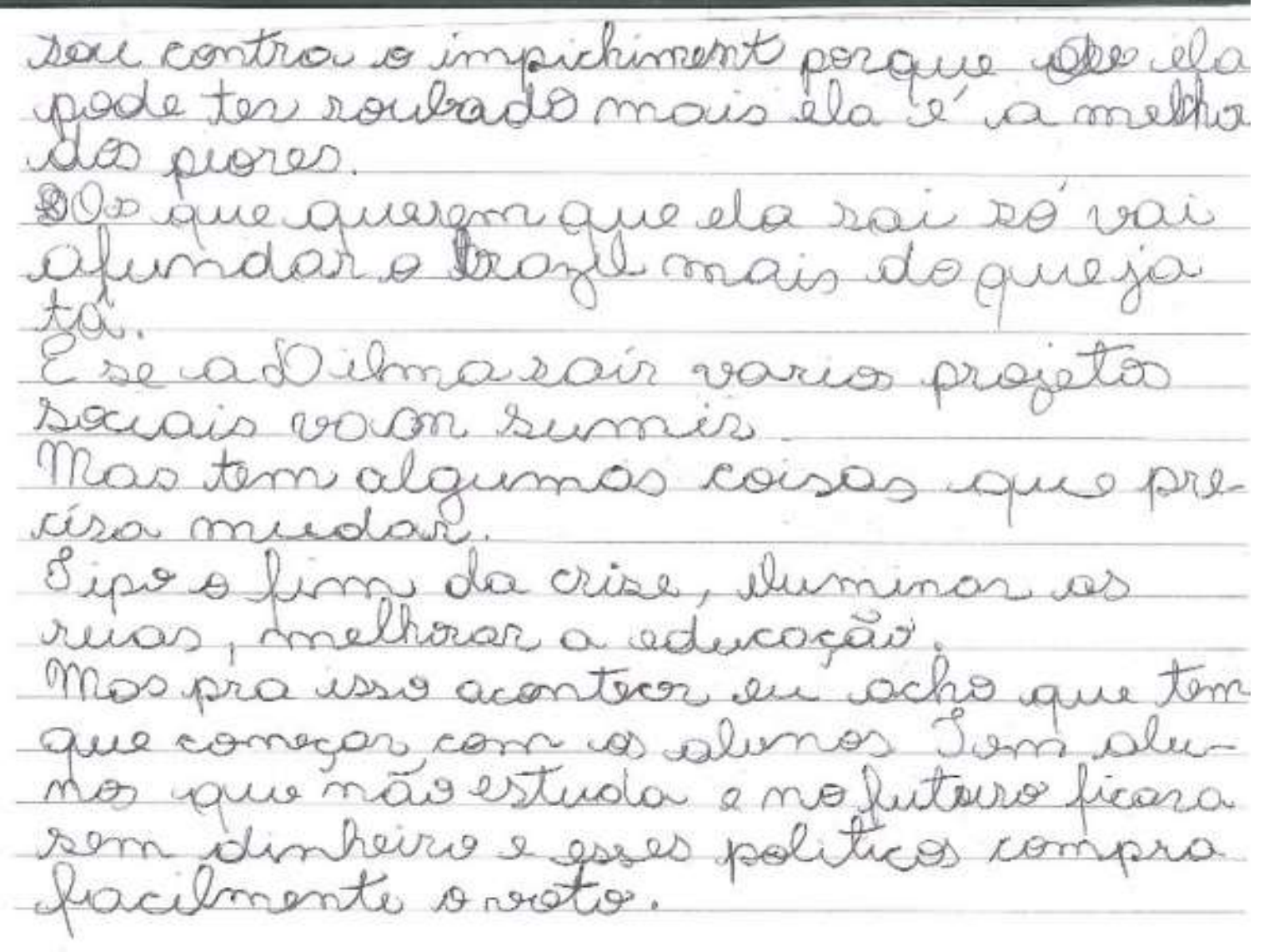

Constatamos, no texto dois, as seguintes marcas:

a) Erros decorrentes da interferência de regras fonológicas categórica no dialeto estudados:

- Supressão de um fonema no interior da palavra: "pra" no lugar de "para". Isso é decorrente da interferência de regras fonológicas categóricas no dialeto.

b) Erros decorrentes da interferência de regras Fonológicas variáveis graduais:

- Supressão da consoante /r/ em: "melho".

c) Erros decorrentes da interferência de regras Fonológicas variáveis descontínuas

- " "tá" ao invés de "está". O verbo "estar" sofre contrações no coloquial e principalmente na oralidade. Além disso, a forma oral "tá" é resultado de mudança linguística que ocorre por conta da aquisição linguística. Isso é língua natural: aquisição e mudança ao mesmo tempo; tanto a sociolinguística quanto o gerativismo defendem que a variação linguística é na verdade mudança linguística, a aquisição é um processo contínuo de mudança linguística que coloca a ação do falante adquirindo como uma forma dialética que ao aprender também modifica e oferece novas idiossincrasias aos sistemas e às normas.

- "vaon" ao invés de "irão".

\section{d) Outras Marcas:}

- Problemas com o emprego de pontuação que pode ser influência das atividades conversacionais, sem pausas, falas seguidas/contínuas (sou contra o impchiment porque ela pode ter roubado mas ela é a melhor dos piores). Isso dificulta a compreensão do texto e nos leva a pensar que 
o aluno utiliza tal ação por entender que a fala

é contínua.

Texto 3. Análise das produções dos alunos

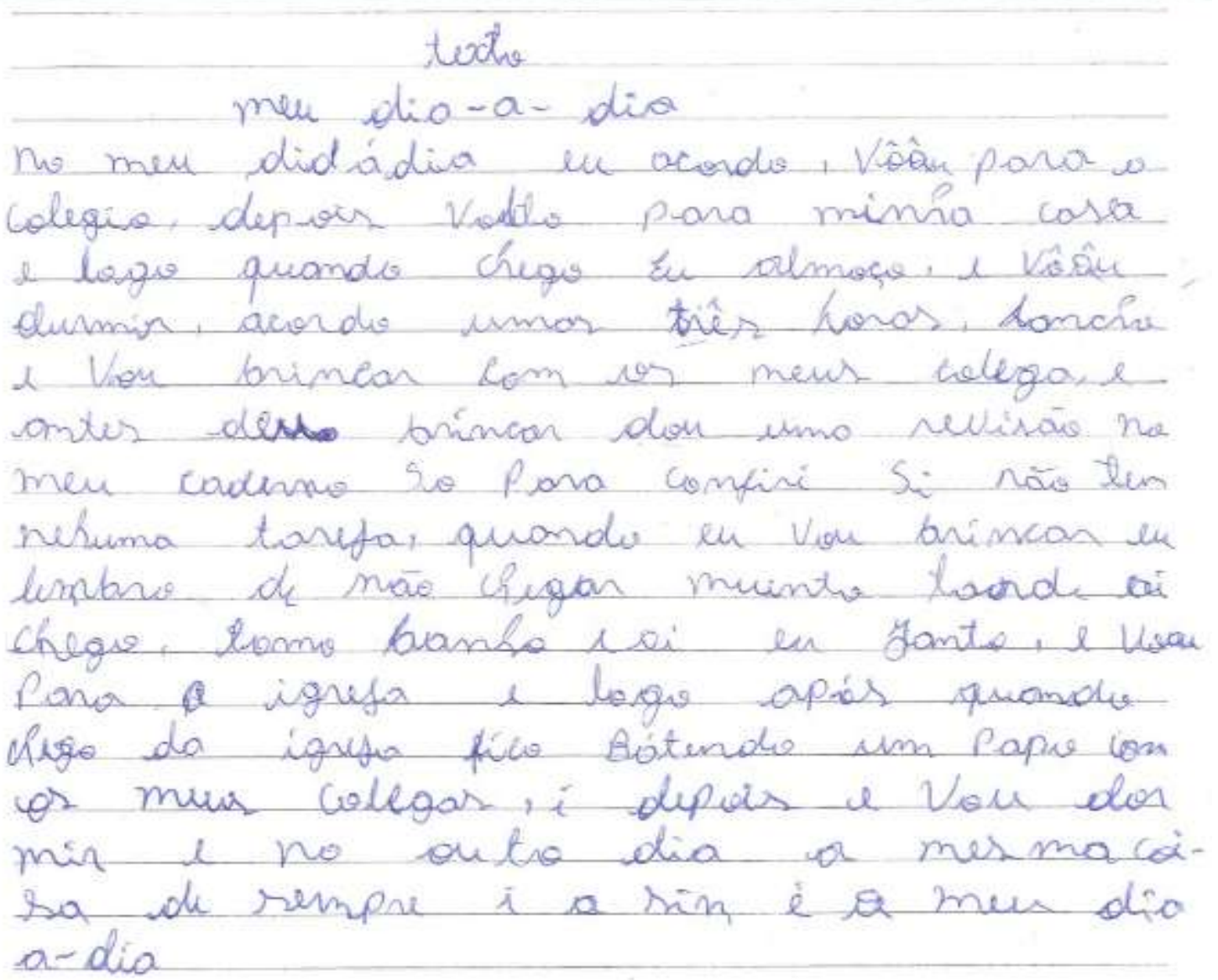

a) Erros decorrentes da interferência de regras fonológicas categórica no dialeto estudados:

- Vogal /i/ no lugar da vogal /e/, pois, ao invés de escrever /se/, escreve /si/ . Há uma troca de som dos fonemas.

- Troca da vogal /o/ pela vogal /u/ em 'durmir';

- Troca da vogal /e/ pela vogal /i/ em 'confiri';

Cagliari (1993, p. 138-139) afirma que "o erro mais comum dos alunos é caracterizado por uma transcrição fonética da própria fala [...]”. b) Erros decorrentes da interferência de regras Fonológicas variáveis graduais:

- Supressão da consoante $/ r /$ de infinitivo em: "confiri".

c) Erros decorrentes da interferência de regras Fonológicas variáveis descontínuas

- Transposição da fala para a escrita como "vôôu" ao invés de "vou".

Nesta categoria, estão incluídos os desvios ortográficos que, conforme BortoniRicardo (2005), seriam, geralmente, provenientes de variedades rurais e/ou submetidas a forte avaliação negativa. 


\section{d) Outras marcas:}

- Usos de gírias como "aí", uma marca da oralidade na escrita, pois, no contexto em que o aluno a inseriu, não pede a utilização dessa expressão.

Texto 4. Análise das produções dos alunos

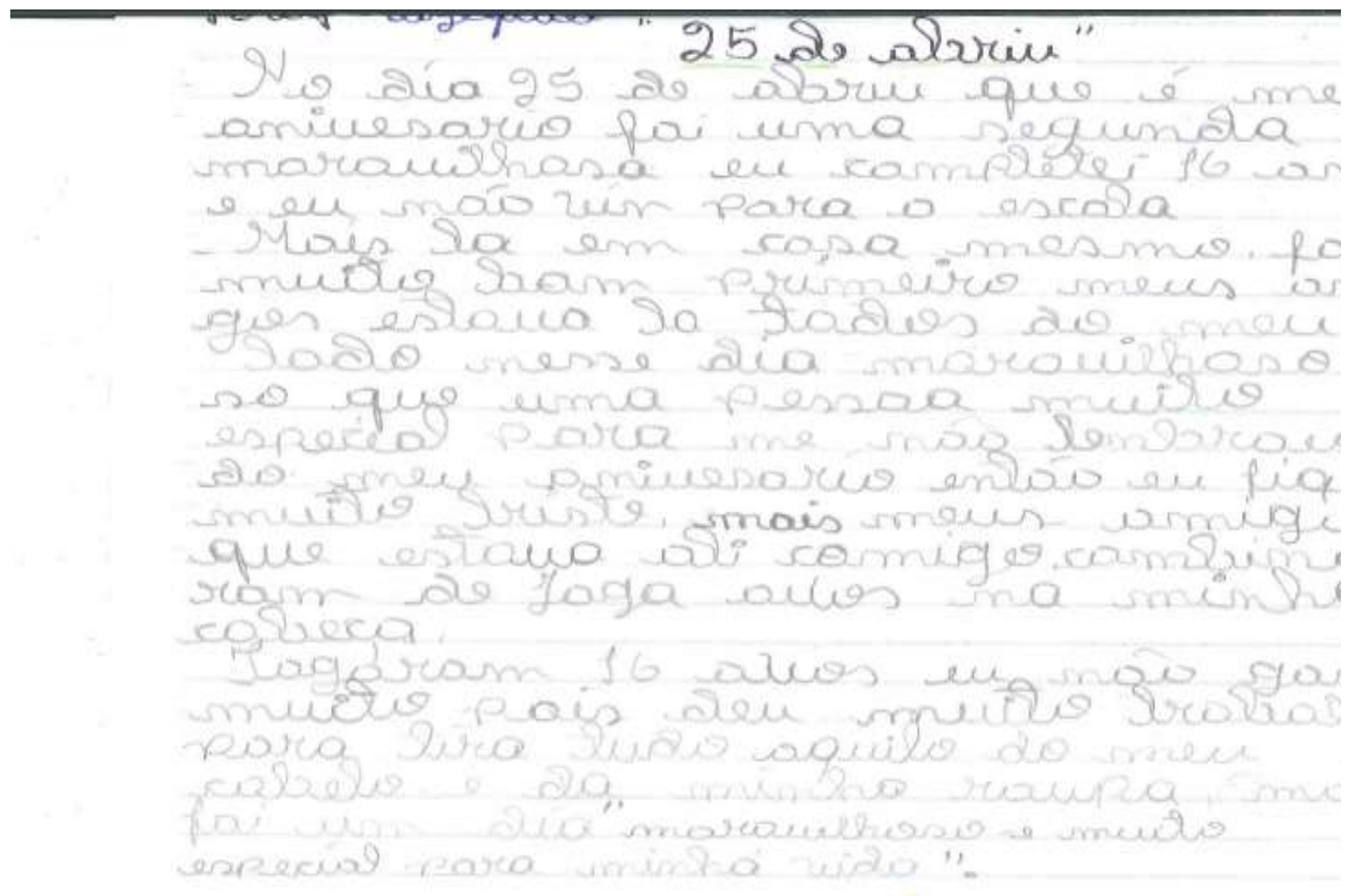

a) Erros decorrentes da interferência de regras fonológicas categórica no dialeto estudados:

- Troca do som da consoante /l/ pela vogal /u/, pois escreve "abril" como se pronuncia "abriu". O som/fonema /u/ de abril é representado pelo grafema "l", ele não tem som lateral de $/ 1 /$, apenas em algumas pronúncias específicas, como em partes do sul do Brasil. Se o aluno pronunciasse realmente $/ 1 /$, ele dificilmente escreveria abril com $u$.

b) Erros decorrentes da interferência de regras Fonológicas variáveis graduais:

- Supressão da consoante /r/ de infinitivo em: 'joga'; ‘tira.
$\mathrm{Na}$ fase de ensino em que os alunos se encontram (Ensino Médio), seria interessante que não encontrássemos registros orais no texto escrito, pois se trata de estudantes que já deveriam ter uma demanda bastante significativa de leituras, a fim de que utilizassem o conhecimento acumulado da língua no momento da produção escrita.

\section{CONSIDERAÇÕES FINAIS}

Este artigo buscou demonstrar as inadequações ortográficas que implicam marcas de oralidade de alunos do segundo ano do Ensino Médio, numa escola pública no município de Porto Nacional - TO. 
Questionamos quais seriam as influências/marcas da linguagem oral nos textos escritos de alunos do Ensino Médio? Como lidar, no ensino, com estas marcas e como revertê-las nas gramáticas do português padrão?

Em relação ao primeiro questionamento, verificamos que as marcas de oralidade mais recorrentes nos textos escritos analisados foram: neutralização de vogais átonas, falta de pontuação adequada (remetendo a atos conversacionais), presença dos marcadores conversacionais e, principalmente, a escrita próxima da transcrição fonética. Nessas recorrências, fica evidente o desconhecimento das normas gramaticais, o que ocasiona a dificuldade dos discentes de se apropriaram da diferença de uso da modalidade oral e a escrita.

Quanto ao segundo questionamento, averiguamos que a oralidade ainda influencia de maneira significativa a escrita, pois os alunos não possuem as demandas necessárias para uma boa escrita, para diferenciar registros orais $\mathrm{e}$ escritos da língua.

Constatamos também que o fato dos alunos terem pouco conhecimento das regras gramaticais ou pouco domínio da norma culta da língua é o que também pode influenciar para as marcas de sua fala na escrita. Dessa forma, compreendemos ser necessário a intensificação de aula voltadas para o ensino de inadequações ortográficas e do Português Padrão, levando em consideração o contexto sócio-cultural do aluno, pois segundo os PCN
[...] A questão não é falar certo ou errado, mas saber qual forma de fala utilizar, considerando as características do contexto de comunicação, ou seja, saber adequar o registro às diferentes situações comunicativas. É saber coordenar satisfatoriamente o que falar e como fazêlo, considerando a quem e por que se diz determinada coisa. (BRASIL, 1998, 26).

Diante do exposto, compreendemos que encontrar a presença da oralidade na escrita dos alunos do Ensino Médio nos ajuda a refletir e repensar nossas práticas pedagógicas para o desenvolvimento da linguagem nesta modalidade, pois se espera que estes alunos dominem, mesmo que de forma mediana, as convenções da língua.

Destarte, atividades que possam desenvolver a modalidade oral e escrita, devem ser (re)pensadas com o intuito de possibilitar aos sujeitos envolvidos maior conhecimento e familiaridade com as duas modalidades, diminuindo assim, os índices de inadequações ortográficas. Além disso, os alunos enriquecerão mais o seu vocabulário, produzindo textos de forma compreensível para os seus interlocutores.

Por fim, compreendemos que esta pesquisa teve relevância ao nos permitir refletir acerca do porquê os alunos ainda utilizam de maneira tão marcante a oralidade em seus textos. Além disso, esta pesquisa possibilita uma abertura de caminhos para novas pesquisas acerca do desenvolvimento da linguagem oral.

Todos os autores declararam não haver qualquer potencial conflito de interesses referente a este artigo. 


\section{REFERÊNCIAS}

ARAÚJO, C. M.; BARBOSA, S. R. S. Crônica: gênero textual a serviço da formação de leitores. Interdisciplinar. Edição Especial, ABRALIN/SE, Itabaiana/SE, Ano VIII, v.17, jan./jun. 2013.

BATISTA-SANTOS, D. O. Um modelo didático do gênero cordel: uma contribuição para o ensino e aprendizagem de gênero. São Paulo, SP. Dissertação de Mestrado em Linguistica Aplicada e Estudos da Linguagem. Pontifícia Universidade Católica de São Paulo - PUC; 2014.

BESSA, R. J, DAYANE, O.M. LIDIANE, D. B. Um estudo sobre a influência da oralidade na aquisição da escrita de alunos do Ensino Fundamental de nove anos. Ideação. V. 14 - no 2 - p. 199-214. $2^{\circ}$ sem. 2012. Foz do Iguaçu.

BORTONI-RICARDO, S. M. Do campo para a cidade: estudo sociolinguístico de migração e redes sociais. São Paulo: Parábola, 2004.

. Nós cheguemu na escola,

e agora? Sociolinguística e educação. São Paulo: Parábola, 2005. . 2004. Educação em língua materna: a sociolinguística na sala de aula. São Paulo: Parábola.

BORTONI-RICARDO, S. M. 2006. O estatuto do erro na língua oral e na língua escrita. In: GORSKI, Edair M.; COELHO, Izete L. (Org.). Sociolinguística e ensino: contribuições para a formação do professor de língua. Florianópolis: Ed. da UFSC.

BOTELHO, José Mario. A natureza das modalidades oral e escrita. In: Filologia, linguística e ensino. Tomo 2, V. IX, n. 03. CiFEFIL: Rio de Janeiro, 2005, p. 30-42.

BRASIL. Secretaria de Educação Fundamental. Parâmetros Curriculares Nacionais: terceiro e quarto ciclos do ensino fundamental: introdução aos parâmetros curriculares nacionais. Brasília: MEC/SEF, 1998.
CAGLIARI, L. C. Alfabetização \& linguística. 6. ed. São Paulo: Scipione, 1993.

CASTILHO, A. T. A língua falada no ensino de português. São Paulo: Contexto, 1998.

FÁVERO, L. L.; ANDRADE, M. L. C. V. O.; AQUINO, Z. G. O. Oralidade e escrita: perspectivas para o ensino de língua materna. São Paulo: Cortez, 2000.

FRANÇA, J. M. Por uma prática da oralidade nas aulas de língua materna: escrita, letramento e gênero textual. Linguasagem. V.1 $5^{\mathrm{a}}$ edição. 2009. Disponível em: http://www.letras.ufscar.br/linguasagem/edicao 05/ Acesso em: 20/11/2016.

KATO, M. A. No mundo da escrita: uma perspectiva psicolinguística. 7. ed. São Paulo: Ática, 2002.

KOCH, I. V. O texto e a construção dos sentidos. 8. ed. São Paulo: Contexto, 2005.

MARCUSCHI, L. A. Produção textual, análise Editorial, 2008.

Da fala para a escrita: atividades de retextualização. 10 ed. São Paulo: Cortez, 2010.

Concepção de língua falada nos manuais de português de $1^{\circ}$. e $2^{\circ}$. Graus: uma visão crítica. Trabalhos em Linguística Aplicada, v. 30, p. 39-79, 1997.

NOBRE, L. L. FÁVERO. T. O. Influência da linguagem oral na escrita. Porto Alegre, RS. Trabalho de Conclusão de Curso. Universidade Federal do Rio Grande do Sul UFRGS; 2011.

SOUZA, D. S. G. A Influência da Internet no Domínio da Escrita: Análises e Inferências. Dissertação de Mestrado. Florianópolis, SC. Universidade Federal de Santa Catarina UFSC; 2001. 